\title{
Male scientists share more — but only with other men
}

\section{Evolutionary differences blamed for squeezing out female researchers.}

\section{Jo Marchant}

12 October 2017

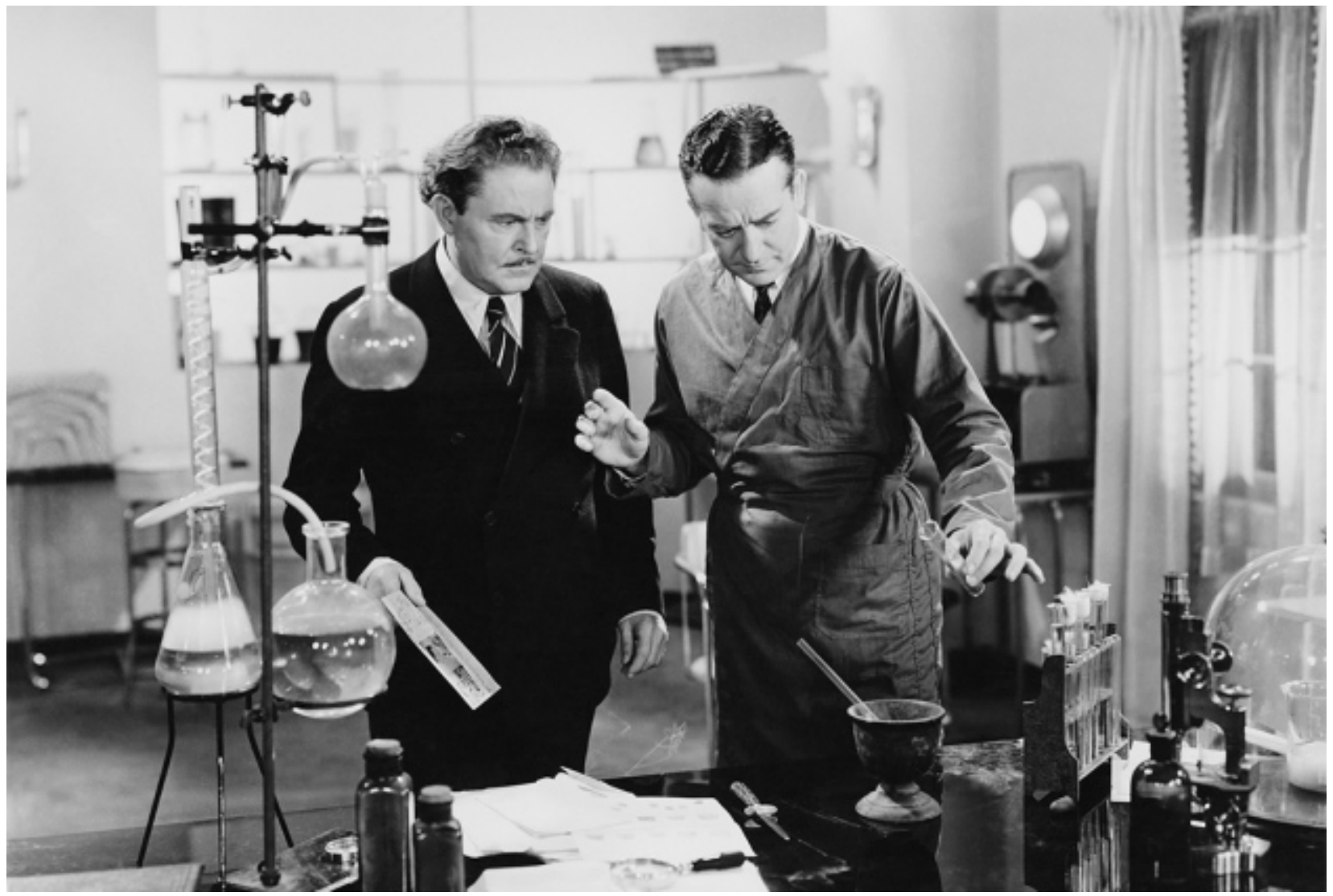

Old Visuals/Everett Coll./Mary Evans Picture Library

Male scientists are more likely to collaborate with other men than with women, says a study.

Male scientists are more likely to share their published work than are women - but only with other men, a study of hundreds of researchers has found.

Humans are generally considered to be a highly cooperative species, says Jorg Massen, a cognitive biologist at the University of Vienna. But most of the evidence for that assumption comes from artificial situations such as computerized cooperation tasks. "I wanted to test human prosociality in an everyday 
situation," he says. So he chose one of the most competitive situations he could think of: his own field of research psychology.

To investigate cooperation among psychologists, Massen turned his fellow researchers into guinea pigs. He and his colleagues e-mailed nearly 300 researchers and asked them to share either a PDF of one of their latest papers, or some raw data (pretending that they wanted to include it in a metaanalysis). The results were published in Scientific Reports on 10 October $^{1}$. In general, the scientists contacted were highly cooperative, with almost $80 \%$ willing to share a PDF and almost $60 \%$ willing to send raw data. "I was surprised," says Massen. "Humans are prosocial even in this competitive field."

Even more unexpected, however, was a strong gender difference in how the scientists responded to the request for help. Massen and his colleagues had wondered whether men might respond more favourably to women, or vice versa. In fact, men were more likely to share, but only with other men. A male-male request was $15 \%$ more likely to be granted than any other gender combination.

\section{Related stories}

- To reduce gender biases, acknowledge them

- Gender bias distorts peer review across fields

- Patchy progress on fixing global gender disparities in science

More related stories

\section{Related stories}

- To reduce gender biases, acknowledge them

- Gender bias distorts peer review across fields

- Patchy progress on fixing global gender disparities in science

More related stories

\section{Evolution at work?}

Massen and his colleagues say that one possible explanation for their results "may be that among male academics there is a network at play, in which they favor each other much like 'Old Boy' networks". They also suggest that this imbalance might have evolutionary roots and point to an idea called the male-warrior hypothesis, which states that men have evolved to form strong bonds with other males in their group because in the past this enabled them to defend territory from hostile attackers.

"Men are more ready to cooperate with genetic-stranger males to form these fighting coalitions," says Mark van Vugt, an evolutionary psychologist at the Free University of Amsterdam who first suggested the theory in $2007^{2}$. Some of the evidence for this idea comes from lab-based tasks such as publicgoods games (in which volunteers choose how many tokens to keep or share), but there are some real-world hints too, he says. Boys tend to play in larger groups than girls, van Vugt says, and in sports 
such as tennis and boxing, men make more effort to bond with their opponent after a match or fight than women do. However cultural factors are also thought to be at work.

Massen's results "sit very well" with these previous findings, says van Vugt, who suggests that such gender differences might affect professional situations beyond psychology research. Any roles that involve teaming up with strangers - such as business, politics, law and economics — could end up favouring men, he predicts. "Men are always on the lookout to find coalition partners," he says, whereas women tend to be more cautious about cooperating with strangers. "That's an obstacle to building up the same networks that men have."

Many factors, including cultural ones, contribute to gender bias at work. "It is very clear that in science and many other professions, women are discriminated against," says Massen. "Something needs to change." But he suggests that an increased awareness of differences in cooperation might encourage both men and women - in science and other fields — to look at their own behaviour and consider how they might respond differently. "I hope people read it and think about it," he says.

Nature doi: $10.1038 /$ nature.2017.22820

\section{References}

1. Massen, J. J. M, Bauer, L., Spurny, B., Bugnyar, T. \& Kret, M. E. Sci. Rep. 7, 12927 (2017).

2. van Vugt, M., De Cremer, D. \& Janssen, D. P. Psychol. Sci. 18, 19-23 (2007). 